\title{
Internal thoracic artery patch repair of a saccular left main coronary artery aneurysm
}

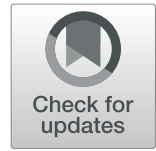

Tomohiro Iwakura* ${ }^{*}$, Kouji Toguchi, Ippei Kato and Noriko Asakawa

\begin{abstract}
Background: A saccular aneurysm located at the bifurcation of the left main coronary artery (LMCA) is an extremely rare condition. A major cause of left main coronary aneurysm is atherosclerosis, and common complications include thrombosis, embolism, and rupture. Despite the serious nature of this condition, the ideal operative approach to LMCA aneurysm (LMCAA) has not been established. Furthermore, little is known about resection of the saccular aneurysm and closure using a small internal thoracic artery patch.
\end{abstract}

Case presentation: Here, we present the case of a 66-year-old woman who had significant stenosis in the left anterior descending artery and a saccular aneurysm at the bifurcation of the LMCAA, which was repaired using a small internal thoracic artery patch during coronary artery bypass grafting. Postoperative multislice computed tomography revealed the complete disappearance of the aneurysm and a successful repair with no luminal stenosis of the internal thoracic artery patch. In addition, the left internal thoracic artery graft was found to be patent.

Conclusions: Resection of the saccular LMCA aneurysm and closure using a small internal thoracic artery patch is safe and offer excellent results.

Keywords: Coronary artery aneurysm, Left main coronary artery, Saccular aneurysm, Internal thoracic artery patch repair, Coronary bypass grafting, Stenosis

\section{Background}

A saccular aneurysm located at the bifurcation of the left main coronary artery (LMCA) is extremely rare, having been recorded in only 22 of 22,000 (0.1\%) catheterizations by Topaz et al. [1] The anatomic location of the aneurysm and involvement of the coronary artery can complicate interventions. As a result, the ideal operative approach for an LMCA aneurysm (LMCAA) is still unclear. In this report, we present the case of successful surgical resection of a saccular LMCA aneurysm and closure using a small internal thoracic artery patch and concomitant construction of a left internal thoracic artery (LITA) graft to address significant stenosis in the left anterior descending (LAD) artery.

\section{Case presentation}

A 66-year-old woman presented at a hospital with chest pain. Her history included diabetes, hypertension, and hyperlipidemia. On examination, the patient

\footnotetext{
* Correspondence: tomalex5050@gmail.com

Department of Cardiovascular Surgery, Meirikai Chuo General Hospital, 114-0001 Higashi-jyujo Kita-ku, Tokyo, Japan
}

had a pulse of 100 beats/minute and blood pressure of $150 / 80 \mathrm{mmHg}$. Her electrocardiogram, echocardiogram, and blood test results were normal. Multislice computed tomography (CT) showed a saccular LMCA aneurysm and significant stenosis in the LAD artery (Fig. 1). Coronary angiography revealed a saccular LMCA aneurysm measuring $9.8 \times 7.5 \mathrm{~mm}$ with $75 \%$ stenosis in the proximal portion of the LAD artery. The operation was performed under general anesthesia. A median sternotomy was performed, and after a longitudinal pericardial opening was made, the heart was inspected. The LITA was removed from the inner chest wall in a skeletonized fashion using electric cautery. A distal segment of $1.5-2 \mathrm{~cm}$ was procured and reserved for use as a patch repair. Before aortic cannulation, the ascending aorta was dissected from the pulmonary artery. Under cardiopulmonary bypass, coronary artery bypasses of the left internal thoracic artery to the LAD artery were constructed in the beating heart. After aortic cross-clamping, the LMCA saccular aneurysm was exposed without main pulmonary artery transection. The saccular LMCA

(c) The Author(s). 2019 Open Access This article is distributed under the terms of the Creative Commons Attribution 4.0 International License (http://creativecommons.org/licenses/by/4.0/), which permits unrestricted use, distribution, and 


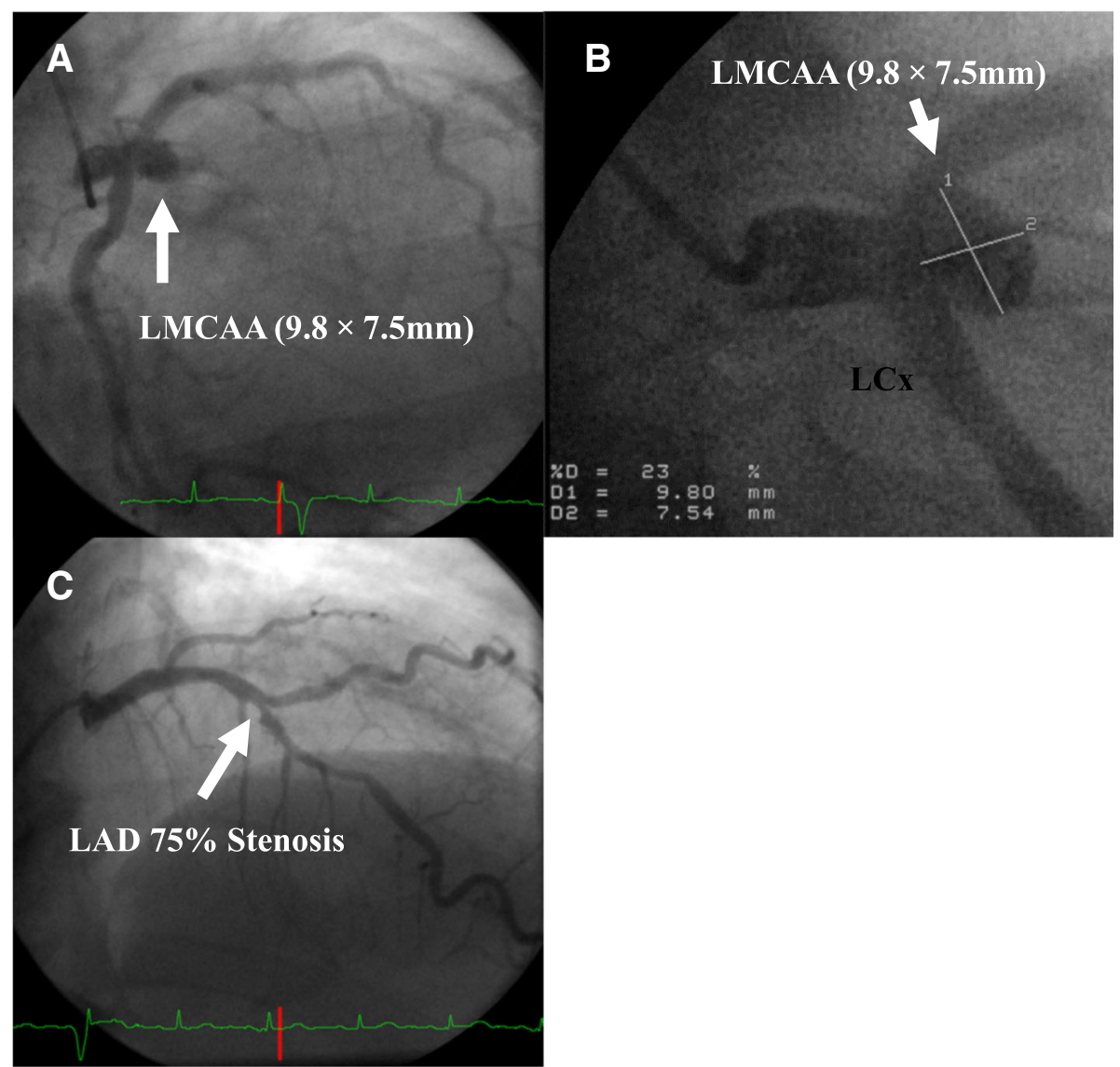

Fig. $\mathbf{1}$ a, b Coronary angiogram showing a saccular aneurysm (arrow) at the left main coronary artery bifurcation. $\mathbf{c}$ Left anterior descending $(\mathrm{LAD})$ arteries (arrow) showing 75\% stenosis. LMCAA: left main coronary artery aneurysm

aneurysm was carefully dissected and completely excised. There was no thrombus in the lumen. Then, the LITA was longitudinally divided and trimmed to fit the incised LMCA. The small internal thoracic artery patch was sutured to the normal and firm lateral coronary arterial wall with a continuous 7-0 Polypropylene suture. Resection of the saccular aneurysm and closure using a small internal thoracic artery patch was then complete. The aortic cross-clamp time was $120 \mathrm{~min}$, and the CPB time was $147 \mathrm{~min}$. The patient had an uneventful hospitalization and was discharged on aspirin therapy. Follow-up multislice CT 10 days after the operation revealed the complete disappearance of the aneurysm and a successful repair with no luminal stenosis by the internal thoracic artery patch. The LITA graft was also found to be patent (Fig. 2). The patient has been followed up yearly since 2009. Fortunately, at the 9-year follow-up, the patient was still asymptomatic, and there were no changes in the ECG and UCG. The patient included in the follow-up had preserved preoperative left ventricular function, and there was no coronary incompetence. Pathology of the aneurysm revealed that the aneurysm wall was very thin due to a lack of trilaminar arterial structure from the remarkable atherosclerotic changes (Fig. 3).

\section{Discussion \& Conclusions}

Several operative approaches have been reported for LMCAA, but there is no consensus on whether ligation, repair, or reconstruction is the most appropriate method [2, 3]. LMCA ligation can occlude the important coronary arteries, and there is a possibility that the access route will be lost when future coronary artery stenosis occurs. If a patient needs percutaneous coronary intervention in the future, patch repair of the LMCAA could enable the use of native circulation for access. In previous studies, the saphenous vein patch was the most common choice, and its failure rate was estimated as $5 \%$ or less [4]. However, it is not clear whether these productive or degenerative changes result in failure; rather, LMCA 


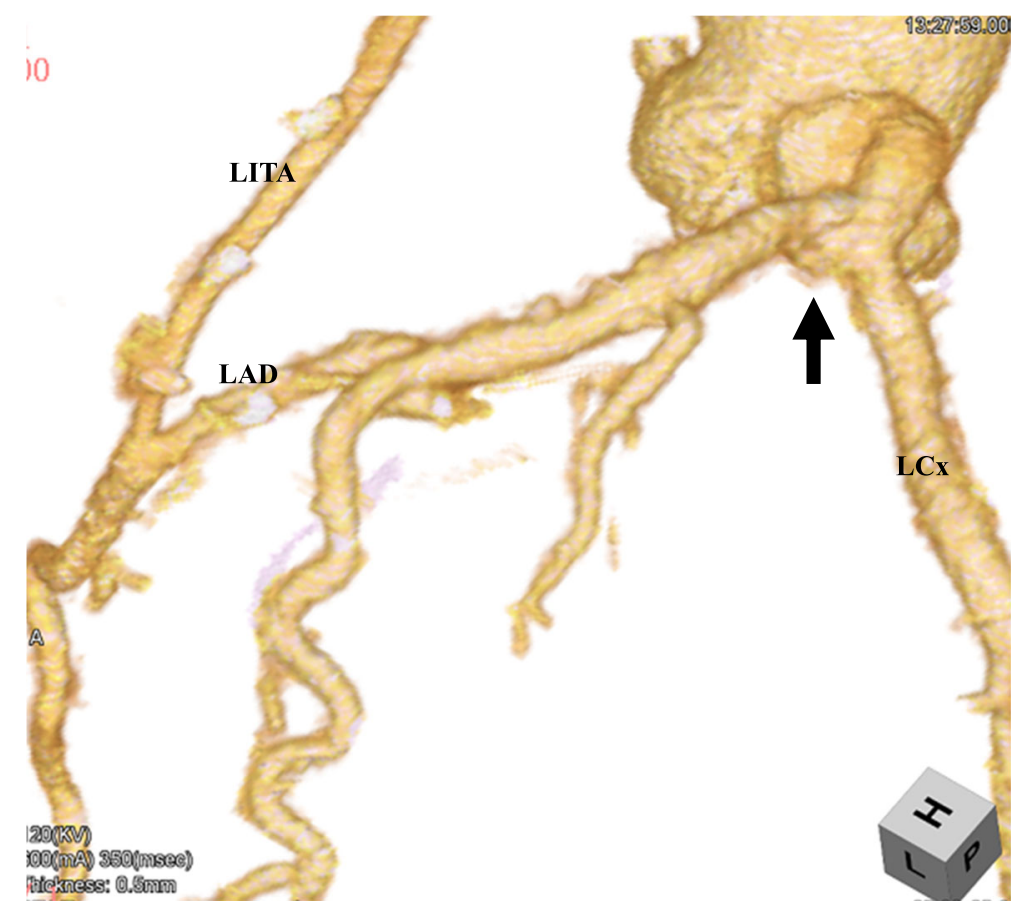

Fig. 2 Multislice computed tomography revealing the repair of the LMCAA (arrow) with an internal thoracic artery patch and patent grafts after surgery. There was no pseudoaneurysm associated with the patch repair. LMCAA: left main coronary artery aneurysm, LAD: left anterior descending artery, LCx: left circumflex artery, LITA: left internal thoracic artery

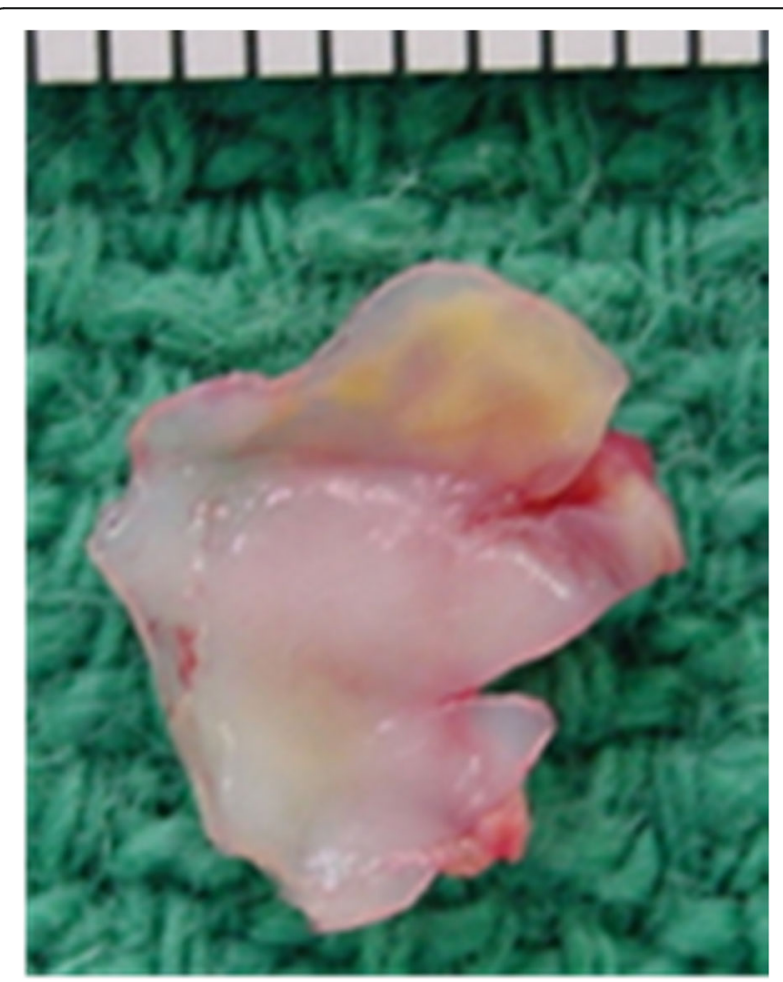

Fig. 3 The resected saccular left main coronary aneurysm specimen showing significant atherosclerosis and partial vessel wall thinning atherosclerosis is seen as the culprit. A small internal thoracic artery patch could decrease the incidence of LMCA restenosis and thrombus formation. Therefore, in the present case, we used the distal segment of the LITA as patch material. The rationale is that the internal thoracic artery better resembles coronary arteries than does the saphenous vein in terms of histologic, physiologic, and fibrinolytic properties [57]. Use of this small internal thoracic artery patch has the advantages of excellent material strength, similarity to coronary arteries, and availability within the operative field [8].

Coronary angiography remains the gold standard for diagnosis and the best method for the evaluation and assessment of an LMCA aneurysm. Both coronary angiography and intravascular ultrasound offer a good definition of vascular dimensions. However, multislice CT scan, an excellent alternative diagnostic method, is recommended as a postoperative follow-up method for these types of repair, especially for the determination of the exact anatomy and its relation to adjacent structures. Additionally, multislice CT scan is less invasive than coronary angiography and intravascular ultrasound.

This case demonstrates that saccular LMCA aneurysm surgical repair using an internal thoracic artery patch is safe and offers excellent results. 


\section{Abbreviations}

CT: Computed tomography; ITA: Internal thoracic artery; LAD: Left anterior descending; LMCA: Left main coronary artery; LMCAA: Left main coronary artery aneurysm

\section{Acknowledgements}

Not applicable.

\section{Funding}

Not applicable.

\section{Availability of data and materials}

Not applicable.

\section{Authors' contributions}

All the authors were involved in the patient's care. KG, IK, and NS prepared the manuscript. All authors revised the manuscript and approved the final manuscript.

\section{Ethics approval and consent to participate}

Not applicable.

\section{Consent for publication}

We have obtained written consent from the patient to publish the medical data in this case report.

\section{Competing interests}

The authors declare that they have no competing interests.

\section{Publisher's Note}

Springer Nature remains neutral with regard to jurisdictional claims in published maps and institutional affiliations.

Received: 8 December 2018 Accepted: 17 February 2019

Published online: 26 February 2019

\section{References}

1. Topaz O, DiSciascio G, Cowley MJ, et al. Angiographic features of left main coronary artery aneurysms. Am J Cardiol. 1991;67(13):1139-42.

2. Hwong TM, Arifi AA, Wan IY, et al. Rupture of a giant coronary artery aneurysm due to Kawasaki disease. Ann Thorac Surg. 2004;78:693-5.

3. Firstenberg MS, Azoury F, Lytle BW, et al. Interposition vein graft for giant coronary aneurysm repair. Ann Thorac Surg. 2000;70:1397-8.

4. Malyshev N, Gladyshev I, Safuanov A, et al. Surgical angioplasty of the left main coronary artery and/or proximal segment of the right coronary artery by pulmonary autograft patch. Eur J Cardiothorac Surg. 2004;25:21-4.

5. Yang Z, Oemar BS, Carrel T, Kipfer B, Julmy F, Luscher TF. Different proliferative properties of smooth muscle cells of human arterial and venous bypass vessels: role of PDGF receptors, mitogen-activated protein kinase, and cyclin-dependent kinase inhibitors. Circulation. 1998:97:181-7.

6. Dahm PL, Bodelsson M, Tornebrandt, et al. Binding of [3H]-5-hydroxytryptamine to human coronary artery and bypass graft vessels. Cardiovasc Res. 1996;31:800-6.

7. Canham PB, Finlay HM, Boughner DR. Contrasting structure of the saphenous vein and internal mammary artery used as coronary bypass vessels. Cardiovasc Res. 1997;34:557-67.

8. Jönsson A, Jensen J, Olsson A, et al. Follow-up of patients operated on with arterial patch angioplasty of the left main coronary artery. Ann Thorac Surg. 2006;81:1249-55.

Ready to submit your research? Choose BMC and benefit from:
- fast, convenient online submission
- thorough peer review by experienced researchers in your field
- rapid publication on acceptance
- support for research data, including large and complex data types
- gold Open Access which fosters wider collaboration and increased citations
- maximum visibility for your research: over 100M website views per year
At BMC, research is always in progress.
Learn more biomedcentral.com/submissions

